\title{
The prevalence of self-reported neck pain in rugby union players in Gauteng Province
}

\author{
E D Watson, MSportSc, Hons (Biokinetics); R-L Hodge, BHSc (Hons) (Biokinetics); M Gekis, BHSc (Hons) (Biokinetics) \\ Centre for Exercise Science and Sports Medicine, School of Therapeutic Sciences, Faculty of Health Sciences, University of the Witwatersrand, \\ Johannesburg, South Africa
}

Corresponding author: E D Watson (estelle.watson@wits.ac.za)

Background. Rugby is a highly demanding sport that carries a high risk of injury, specifically to the neck region. Repetitive loading of the neck during the scrum or tackle phase may increase neck symptoms and pain.

Objectives. The objective of this cross-sectional, descriptive study was to determine the prevalence of self-reported neck pain in rugby union players in Gauteng Province, South Africa.

Methods. One hundred rugby union players of a mean \pm standard deviation age of $22.1 \pm 2.4$ years, height $1.84 \pm 0.07 \mathrm{~m}$ and weight $95.3 \pm 15.2 \mathrm{~kg}$, completed the four-part questionnaire.

Results. We found a $12 \%$ prevalence of current neck pain, and $52 \%$ of the players reported experiencing previous neck pain. Neck pain was more frequently reported in forwards, with the tackle being the most commonly stated cause. Eighteen players reported mild to moderate disability as a result of neck pain. The players reported that neck strengthening, on-field treatment and coaching could be improved to prevent neck pain.

Conclusion. Current and previous neck pain is prevalent in rugby union players. Neck pain may be a sign of underlying pathology; therefore, players presenting with chronic or acute neck pain should be assessed thoroughly by a sports physician. Neck conditioning and strengthening should be encouraged in all players to prevent the deleterious effects that rugby union may have on the cervical spine.

S Afr J SM 2014;26(1):26-30. DOI:10.7196/SAJSM.512

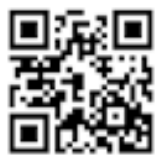

Rugby is a highly demanding, full-contact sport that carries a high risk of injury. Furthermore, the frequency and burden of these injuries appears to have increased with the professionalism of the sport; e.g. the incidence of injury has been estimated to have increased from $47 / 1000$ player hours before professionalism to 74/1 000 player hours after professionalism. ${ }^{[1]}$ Other studies have suggested an even higher incidence of injury of $91-97 / 1000$ player hours. ${ }^{[2]} \mathrm{New}$, previous and recurrent injuries all play a big role in lost playing hours. ${ }^{[2]}$ The most common types of injuries are sprains, strains and contusions. ${ }^{[1,2]}$ The most commonly injured region is the lower limbs, ${ }^{[2]}$ while the prevalence of injuries to the head and neck is estimated at $29-34 \%{ }^{[1]}$ The cervical spine is at particular risk of injury due to its biomechanical design. Unsurprisingly, cervical trauma seems to be a particular risk during the scrum and tackle phase in rugby union. ${ }^{[3]}$ Predictably, forwards have a disproportionally higher risk of cervical injury due to the forces transmitted during scrummaging. ${ }^{[3]}$

Although not the most common, injuries to the neck may often be the most catastrophic. A study by Noakes et al. ${ }^{[4]}$ found that five schoolboy rugby union players in South Africa (SA) died from spinal cord injuries, while an even higher portion had resultant tetraplegia. There is also increasing awareness of the high amount of 'near miss' injuries - severe injuries to the cervical spine that do not affect the spinal cord. ${ }^{[5]}$ Changes to the rules have brought about a reduction in the incidence of spinal cord injuries; ${ }^{[4,5]}$ however, the incidence of cervical injuries is still high. In a prospective study of spinal injuries over two seasons, Fuller et al. ${ }^{[6]}$ found no catastrophic injuries; however, three players sustained career-ending injuries. Minor or non-catastrophic injury to the cervical spine is common, with the incidence ranging from $0.26-9.17 / 1000$ player hours. ${ }^{[7]}$ In amateur rugby union players, $69 \%$ of neck injuries are minor, $17 \%$ mild and $7 \%$ moderate to severe. ${ }^{[8]}$ These injuries may result in neck symptoms, ${ }^{[9]}$ reduced playing time, and associated healthcare costs. Furthermore, the cumulative consequences of these injuries have resulted in premature and advanced degenerative changes in the cervical spine in rugby union players. ${ }^{[10]}$ In a study by Hogan et al., ${ }^{[11]}$ front-row rugby union players presented with asymptomatic, yet significant degenerative changes of the disc spaces and apophyseal joints. Castinel et al., ${ }^{[12]}$ using static magnetic resonance imaging (MRI), found that over half of the rugby union players in their cohort presented with abnormalities of the cervical spine. Furthermore, changes in the active range of motion have also been documented. ${ }^{[13]}$

Therefore, neck pain is theorised to be prevalent in rugby union players, especially forwards. Indeed, Gemmell et al. ${ }^{[9]}$ found an $83 \%$ prevalence of neck pain in forwards compared with a $41 \%$ prevalence in back-row players. There is much research on incidence of injuries; however, very little research has been done on the prevalence of selfreported neck pain in rugby union players in SA. 


\section{Methods}

A cross-sectional, descriptive survey was conducted to determine the prevalence of neck pain in rugby union players in Gauteng Province. A four-part questionnaire (available in the online supplementary material - Appendix A) was adapted from the International Rugby Board's (IRB's) injury assessment form ${ }^{[14]}$ and included the Neck Disability Index (NDI). ${ }^{[15]}$ A convenience sample was used and recruitment took place at university rugby union clubs and professional clubs in Johannesburg and Pretoria. Players, aged 18 - 35 years, who were registered with a rugby union club were included in the study. One hundred players from different levels participated in the study. Level of play ranged from professional $(n=23)$, to university first $(n=17)$ and second teams $(n=9)$, with the majority playing for a university residence team $(n=51)$. Players were approached during training sessions, and provided with an information sheet. All participants signed an informed consent form prior to filling out the questionnaire. The study was approved by the Human Research Ethics Committee (HREC) of the University of the Witwatersrand (reference M120401).

\section{Results}

\section{Demographic data}

One hundred male rugby union players participated in the study; 41 played in the backline and 59 were forwards. The selfreported demographic data for the group are shown in Table 1. Mean height and weight were found to be statistically significantly higher in the forward than in the back players. A comparison of the height, weight and age between the professional and amateur players is shown in Table 2. The professional players showed statistically significantly higher values for height and weight and were significantly older than the amateur players.

\section{Neck pain}

When asked whether they had ever been injured due to rugby union, $91 \%$ of the players responded 'yes', 5\% responded 'no' and $4 \% \mathrm{did}$ not comment.

Twelve per cent of the players reported that they were currently experiencing neck pain, and 52\% reported experiencing previous neck pain. All players currently experiencing neck pain were amateurs, and 7 players (14\%) that had previous neck pain played professionally. Nine of the 12 players (75\%) who were currently experiencing neck pain were forwards, while 34 out of the 52 players (65\%) reporting previous neck pain were also forwards. Players who had experienced neck pain $(n=52)$ were asked to select a cause of the pain from a list of options, with rugby union reported as the leading cause ( $n=43$ ) (Fig. 1).

The players who stated that rugby union was the cause of injury $(n=43)$ were then asked to select the position played at the time of injury. The position associated with the highest occurrence of injury was the loose head prop, with ten players (23\%) having been injured while playing in this position. Seven players (16\%) stated that they played tight head prop, and 6 players were playing hooker (14\%). The tight head flank position accounted for $12 \%$ of injuries, and inside centre and lock accounting for $9 \%$ and $7 \%$ of injuries, respectively. The backline position with the highest occurrence of neck injuries was the flyhalf (7\%). The players were then asked whether they were playing in their normal position at the time of injury: $89 \%$ stated that they were, while $9 \%$ stated that they were not, and $2 \%$ did not provide comment. Furthermore, players were asked to select the situation where the injury occurred: the majority $(n=40)$ were injured during a match situation, while a small

percentage were injured during a full contact skills training session $(n=2)$, and during warm-up or 'other' ( $n=1$, respectively). Fig. 2 shows that the main cause of rugby unionrelated neck injury was the tackle $(n=25)$, followed by the scrum $(n=22)$ and collisions $(n=11)$.

Players with neck pain $(n=52)$ were asked to select the course of treatment undertaken: the majority were treated by a physiotherapist (62\%), followed by a doctor (48\%) and a biokineticist (10\%). A further 10\% reported receiving no treatment for their neck pain. Furthermore, these players were asked to state the outcome of the treatment: $64 \%$ had a full recovery, $15 \%$ stated having a partial recovery, $2 \%$ had not recovered and $4 \%$ indicated that they were currently injured. Eight players (15\%) gave no comment.

These players were also asked whether they felt cautious when doing certain activities after their neck pain or injury. Thirty-four players $(65 \%)$ indicated that they were cautious, $23 \%$ responded in the negative, and $12 \%$ gave no comment. The same question was repeated regarding how cautious they were with returning to full-contact rugby union: $44 \%$ answered in the affirmative and the same number stated that they were not cautious; six players $(12 \%)$ gave no comment. The players were also asked to select from a list the length

Table 1. Demographic data of rugby union players

\begin{tabular}{lllll}
\hline & $\begin{array}{l}\text { All }(\boldsymbol{N}=\mathbf{1 0 0}) \\
\text { mean } \pm \text { SD }\end{array}$ & $\begin{array}{l}\text { Backs }(\boldsymbol{N = 4 1 )} \\
\text { mean } \pm \text { SD }\end{array}$ & $\begin{array}{l}\text { Forwards }(\boldsymbol{N = 5 9}) \\
\text { mean } \pm \text { SD }\end{array}$ & p-value \\
\hline Height $(\mathrm{m})$ & $1.84 \pm 0.07^{\dagger}$ & $1.81 \pm 0.07$ & $1.86 \pm 0.07^{*}$ & 0.001 \\
Weight $(\mathrm{kg})$ & $95.30 \pm 15.30^{\ddagger}$ & $84.43 \pm 9.60$ & $102.65 \pm 13.96^{*}$ & 0.000 \\
Age (years) & $22.10 \pm 2.40$ & $21.88 \pm 1.99$ & $22.29 \pm 2.67$ & 0.063 \\
& & & & \\
SD $=$ standard deviation. \\
${ }^{*}$ Statistically significant difference $(p<0.05)$. \\
${ }^{\dagger}$ Missing data $(n=3)$. \\
${ }^{\ddagger}$ Missing data $(n=2)$.
\end{tabular}

Table 2. Demographic differences between professional and amateur players

\begin{tabular}{llll}
\hline & $\begin{array}{l}\text { Professional players }(\boldsymbol{N = 2 3}) \\
\text { mean } \pm \text { SD }\end{array}$ & $\begin{array}{l}\text { Amateur players }(\mathbf{N = 7 6}) \\
\text { mean } \pm \text { SD }\end{array}$ & p-value \\
\hline Height $(\mathrm{m})$ & $1.87 \pm 0.06^{*}$ & $1.83 \pm 0.07^{\dagger}$ & 0.011 \\
Weight $(\mathrm{kg})$ & $105 \pm 11.14^{*}$ & $92.35 \pm 15.17$ & 0.000 \\
Age (years) & $24 \pm 3^{*}$ & $22 \pm 2$ & 0.000 \\
${ }^{*}$ Statistically significant difference $(p<0.05)$. & & \\
${ }^{\dagger}$ Missing data $(n=2)$. & &
\end{tabular}


of time taken to return to normal level of play. The majority of players took one month to return to play (Fig. 3).

\section{Preventive measures}

All players $(n=100)$ were asked whether they felt that there were enough preventive measures to reduce the risk of neck pain during rugby union: $44 \%$ felt that there were not enough measures in place, $55 \%$ said that there were enough measures in place, and $1 \%$ provided no answer. The players who felt that there were not enough measures in place were then prompted to select from a list the factors that needed to be improved. Players were able to select more than one option. The majority felt that neck strengthening was a factor that could be improved upon, as well as on-field treatment and coaching (Fig. 4).

\section{Neck strengthening}

Players were asked whether neck strengthening formed part of their training programme, and if so, how many times a week they performed such training: 56 responded affirmatively, while 43 responded in the negative and one player gave no comment. Most players who answered affirmatively stated that they performed these exercises $1-2$ times per week (Fig. 5).

\section{NDI}

Thirty-one players (60\%) filled out the NDI, and were classified into disability categories according to Vernon. ${ }^{[15]}$ The mean \pm SD NDI score, out of a possible 50 , was $6.7 \pm 4.7$, with the highest score being $23(n=2)$. The rugby union players were classified as having no disability $(n=13)$, mild disability $(n=15)$ or moderate disability $(n=3)$.

The NDI is comprised of 10 categories of daily activities/areas that could be affected by neck pain. To ascertain which area caused the most concern, the total sum of scores was added up for each category (Fig. 6). Pain and headaches were most commonly reported, as well as lifting, reading and sleeping.

\section{Discussion}

It is well known that the incidence of neck injuries in rugby union is high, reported to account for $2-14 \%$ of all injuries. ${ }^{[7]}$ Common injuries incurred include cervical facet joint sprain, neck muscle strain and neuropathy. ${ }^{[8]}$

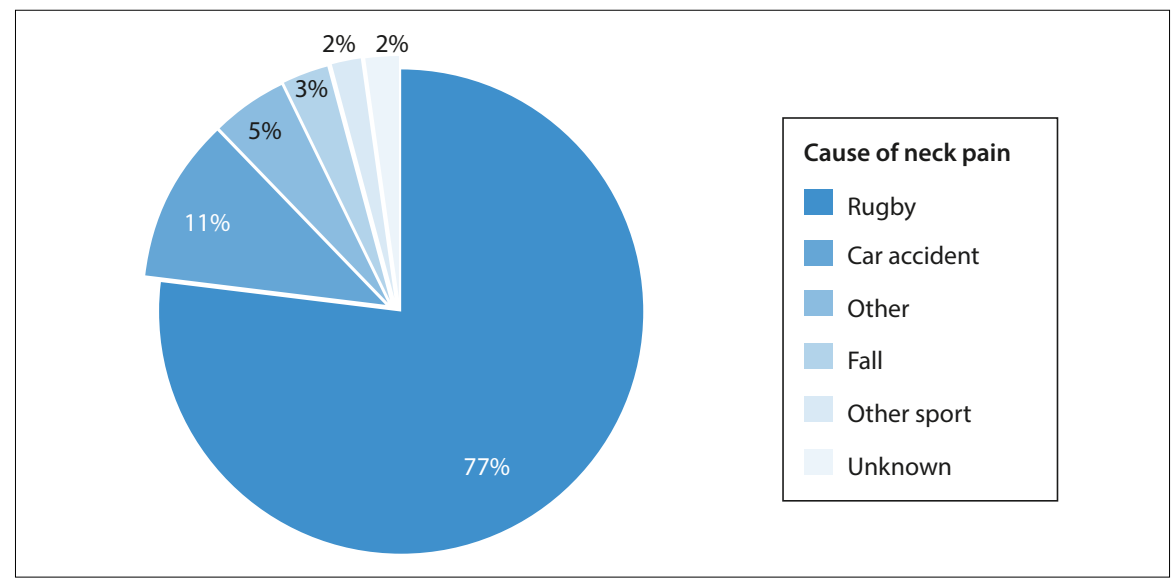

Fig. 1. Cause of neck pain.

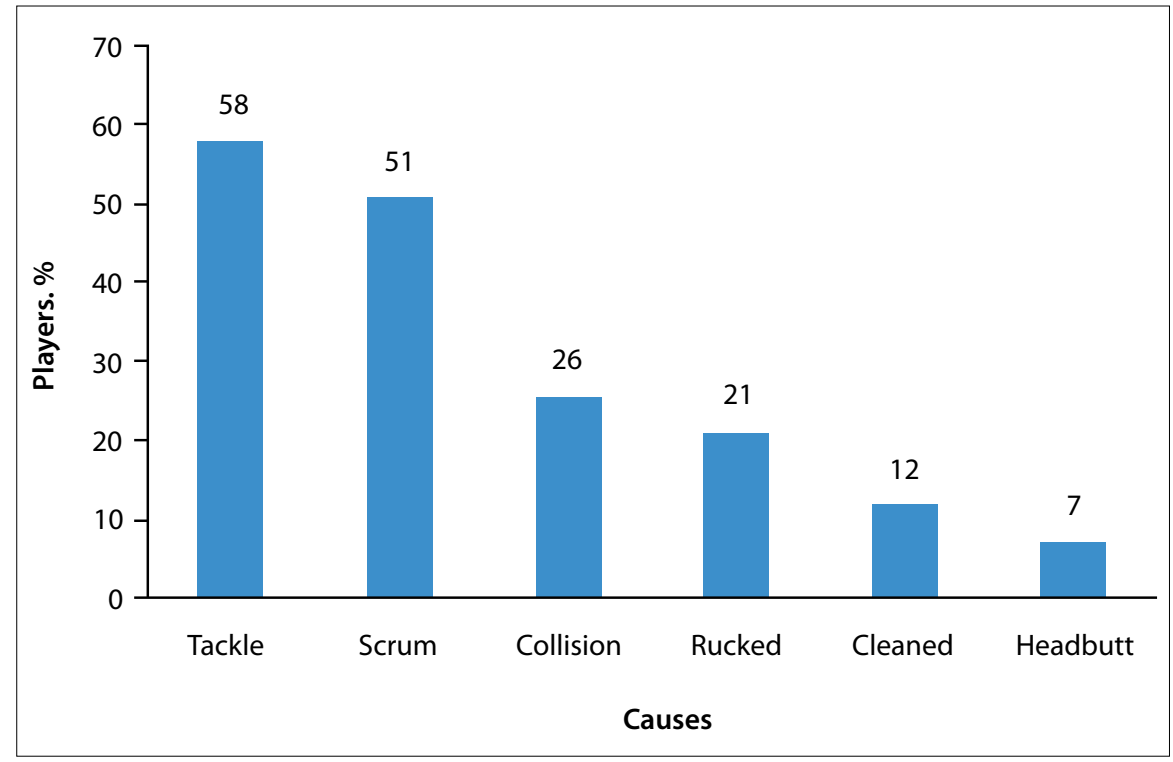

Fig. 2. Cause of rugby-related neck injury.

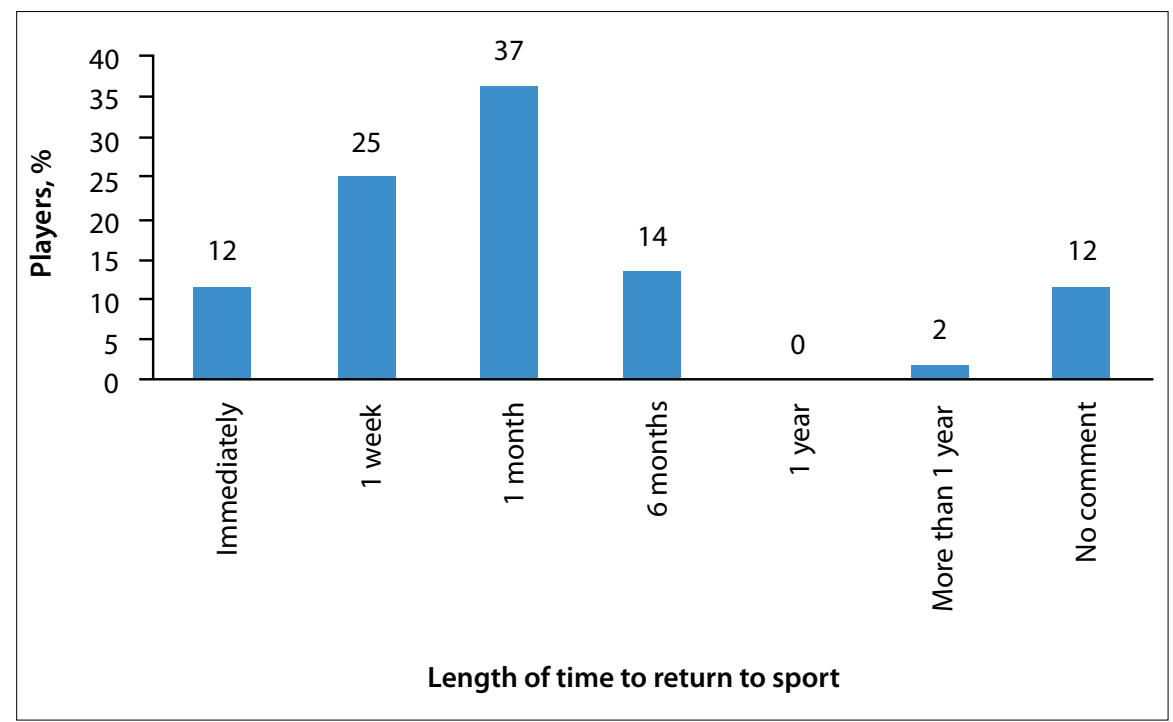

Fig. 3. Length of time taken to return to sport following a neck injury. 
Many studies have addressed the incidence and severity of neck injuries in rugby union, ${ }^{[7,8]}$ but few have addressed the potential lasting effects, or prevalence of neck pain in these players.

It is also common for rugby union to cause pathological changes to the cervical spine; but these changes do not always manifest clinically ${ }^{[11]}$ In addition, repetitive microtrauma from collisions in the scrum has also been associated with insidious, chronic neck pain. ${ }^{[10]}$ Therefore, we undertook this study to determine the prevalence of neck pain in rugby union players in Gauteng Province, SA. Our study indicated a $12 \%$ prevalence of neck pain in rugby union players, with over half of the players having experienced neck pain in the past. Similar to a study by Gemmell and Dunford, ${ }^{[9]}$ our study found a higher prevalence of neck pain in forwards than in backline players. This comes as no surprise, due to the intense repetitive forces on the spine during scrummaging. ${ }^{[16]}$ In addition to the scrum, the tackle appears to be the phase of play where most injuries occur. ${ }^{[17]}$ In the current study, the majority of the rugby-union-related neck injuries reportedly occurred during a tackle, which has been the phase of play found to be the most associated with spinal injuries. ${ }^{[18]}$

A large portion of players in our study felt that there were not enough preventive measures to reduce the risk of neck pain. The main preventive measure suggested by the players was neck conditioning. Strengthening of the neck muscles is an encouraged preventive measure for both injury frequency and severity. ${ }^{[19]}$ Although proper condition of the neck muscles is a practical method of injury prevention, almost half of the players in the current study reported performing no neck strengthening. Du Toit et al. ${ }^{[20]}$ found that neck strength was not adequate to meet the unique positional requirements needed in rugby union; this remains an area in training that still requires improvement. What is more, experienced coaches and knowledgeable medical personnel can aid in making rugby union safer. ${ }^{[19]}$ Similar to the study by Shelly et al., ${ }^{[18]}$ our players reported both on-field treatment and coaching as major contributing factors that can be improved upon. To this effect, SA has implemented the BokSmart programme, training 38500 coaches and referees on rugby union safety. ${ }^{[21]}$ The programme aims to educate coaches,

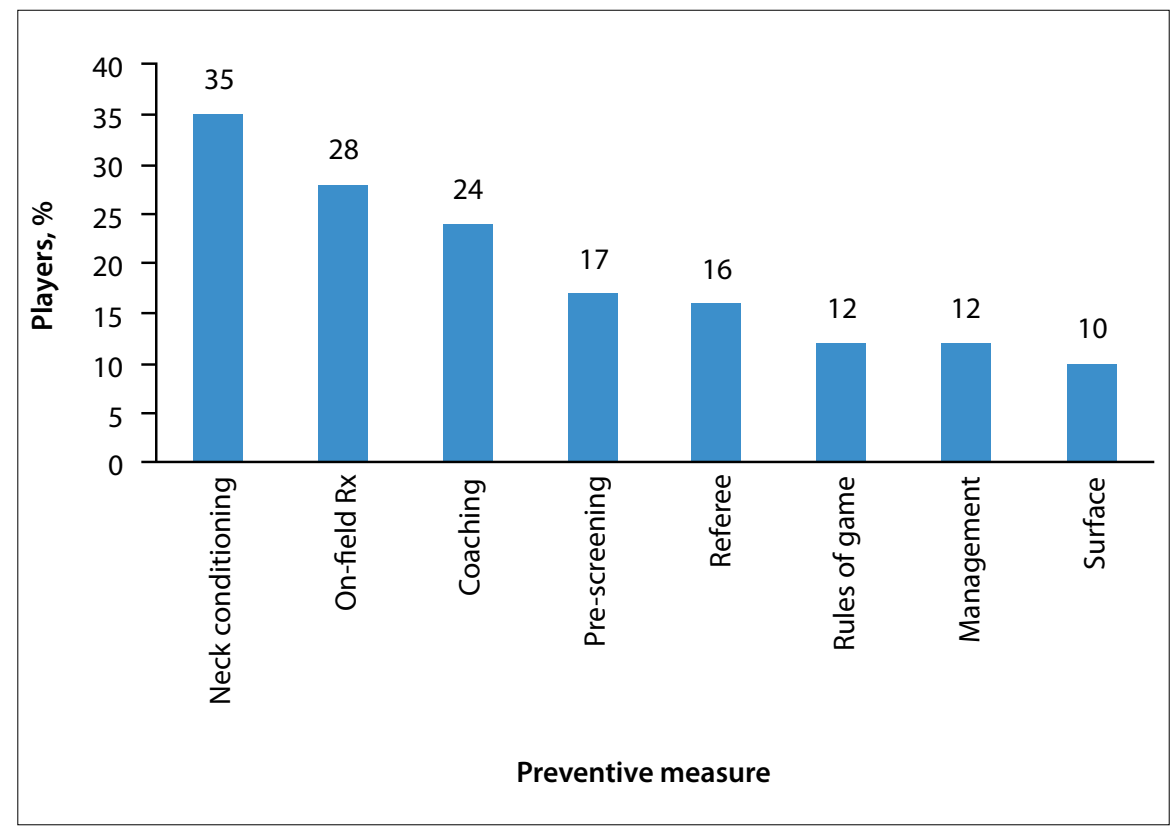

Fig. 4. Players' opinions on factors that could prevent neck injuries. $(R x=$ treatment. $)$

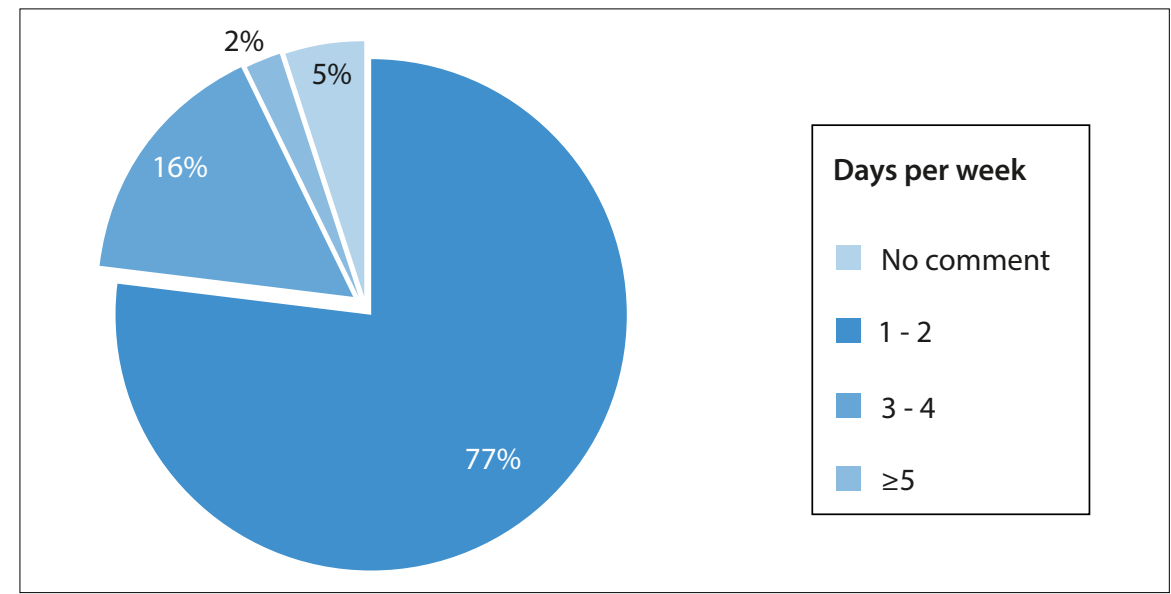

Fig. 5. Frequency of neck strengthening per week.

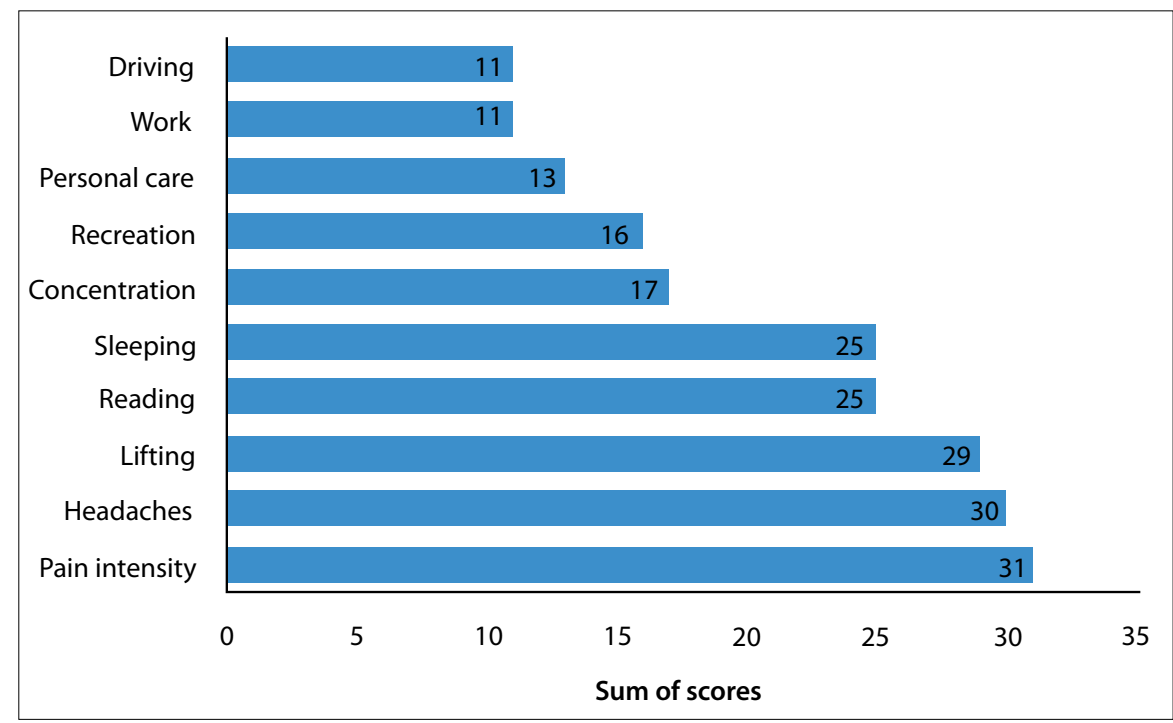

Fig. 6. Total score for each disability category. 
referees and first-aiders on safe rugby union practices, and provide support and educational resources. Furthermore, coaches are equipped to teach correct tackling technique, which may be instrumental in reducing injury risk. ${ }^{[21]}$ However, the question remains whether the players believe this is sufficient, and whether these learned practices are being applied on field. ${ }^{[22]}$

It has been suggested that participation in rugby union can affect the range of movement (ROM) of the neck, leading to mild or moderate disability. ${ }^{[9]}$ In fact, active ROM in rugby union players has been found to be similar to that of whiplash patients. ${ }^{[23]}$ Indeed, in the current study, $18 \%$ of players reported mild to moderate disability from their neck pain, and reported issues such as pain, headaches, and difficulty lifting, reading and sleeping. Even more worrisome is that many studies have radiologically shown degenerative changes in the neck that do not manifest clinically. ${ }^{[11]}$ Therefore, the prevalence of neck pain may not tell the full story of underlying cervical abnormalities. Furthermore, minor injuries and neck pain may be a signpost for more serious neck pathology, and should be assessed accordingly. ${ }^{[10]}$

\section{Study limitations}

Due to the descriptive nature of the study, it is not possible to infer the actual cause of the neck pain reported. Furthermore, the study is limited by the involved interpretation of the term 'injury' by the player. Further studies should include a clinician-diagnosed neck injury to minimise potential bias due to the ambiguity of these concepts. Although our study described self-reported neck pain prevalence in a small number of rugby union players playing for specific clubs within Gauteng Province, it revealed an interesting observation that warrants further investigation on a larger scale.

\section{Conclusion}

This study provides interesting insight into neck pain prevalence in rugby union players in Gauteng Province. The prevalence of current and previous neck pain in this population is high, with neck pain being more prevalent in forwards than backline players. Neck pain caused mild to moderate disability in $18 \%$ of the players. Neck conditioning and strengthening should be encouraged in all players, to prevent to the deleterious effects that rugby union may have on the spine. In addition, players presenting with chronic or acute neck pain should be assessed thoroughly by a sports physician.

Acknowledgements. We thank all the rugby union players who took the time to participate in the research.

\section{References}

1. Bathgate A, Best JP, Craig G, Jamieson M. A prospective study of injuries to elite Australian rugby union players. Br J Sports Med 2002;36(4):265-269. [http://dx.doi. org/10.1136/bjsm.36.4.265]
2. Brooks J, Fuller CW, Kemp S, Reddin DB. Epidemiology of injuries in English professional rugby union: Part 1 match injuries. Br J Sports Med 2005;39(10):757766. [http://dx.doi.org/10.1136/bjsm.2005.018135]

3. Quarrie KL, Cantu RC, Chalmers DJ. Rugby union injuries to the cervical spine and spinal cord. Sports Med 2002;32(10):633-653. [http://dx.doi.org/10.2165/00007256200232100-00003]

4. Noakes T, Jakoet I, Baalbergen E. An apparent reduction in the incidence and severity of spinal cord injuries in schoolboy rugby players in the western Cape since 1990. S Afr Med J 1999;89(5):540.

5. Noakes T, Jakoet I. Spinal cord injuries in rugby union players. BMJ 1995;310(6991):1345-1346.

6. Fuller CW, Brooks JHM, Kemp SPT. Spinal injuries in professional rugby union A prospective cohort study. Clin J Sport Med 2007;17(1):10-16. [http://dx.doi. org/10.1097/JSM.0b013e31802e9c28]

7. Swain MS, Lystad RP, Pollard H, Bonello R. Incidence and severity of neck injury in Rugby Union: A systematic review. J Sci Med Sport 2011;14(5):383-389. [http:// dx.doi.org/10.1016/j.jsams.2010.10.460]

8. Swain MS, Pollard HP, Bonello R. Research incidence, severity, aetiology and type of neck injury in men's amateur rugby union: A prospective cohort study. Chiropr Osteopat 2010;18(18):3-12.

9. Gemmell H, Dunford PJ. A cross-sectional study of the prevalence of neck pain decreased cervical range of motion and head repositioning accuracy in forwards and backs in rugby union. Clinical Chiropractic 2007;10(4):187-194. [http://dx.doi. org/10.1016/j.clch.2007.09.002]

10. O'Brien C. "Rugby neck": Cervical degeneration in two front row rugby union players. Clin J Sport Med 1996;6(1):56-59.

11. Hogan B, Hogan NA, Vos, PM, Eustace SJ, Kenny PJ. The cervical spine of professional front-row rugby players: Correlation between degenerative changes and symptoms. Irish Journal of Medical Science 2010;179(2):259-263. [http:// dx.doi.org/10.1007/s11845-009-0432-3]

12. Castinel BH, Adam P, Milburn PD, et al. Epidemiology of cervical spine abnormalities in asymptomatic adult professional rugby union players using static and dynamic MRI protocols: 2002 to 2006. Br J Sports Med 2010;44(3):194-199. [http://dx.doi.org/10.1136/bjsm.2007.045815]

13. Lark SD, McCarthy P. The effects of a rugby playing season on cervical range of motion. J Sport Sci 2010;28(6):649-655. [http://dx.doi.org/10.1080/02640410600944543]

14. International Rugby Board (IRB). http://www.irbplayerwelfare.com (accessed 1 September 2013).

15. Vernon H. The Neck Disability Index: State-of-the-art, 1991 - 2008. J Manipulative Physiol Ther 2008;31(7):491-502. [http://dx.doi.org/10.1016/j.jmpt.2008.08.006]

16. Preatoni E, Stokes K, England M, Trewartha G. Forces generated in rugby union machine scrummaging at various playing levels. Women 2012;7771:197-297.

17. Garraway W, Macleod D. Epidemiology of rugby football injuries. Lancet 1995;345(8963):1485-1487. [http://dx.doi.org/10.1016/S0140-6736(95)91040-9]

18. Shelly M, Butler JS, Walsh MG, O’Byrne JM. Spinal injuries in Irish rugby: A ten-year review. J Bone Joint Surg Am 2006;88(6):771-775. [http://dx.doi.org/10.1302/0301620X.88B6.17388]

19. Dietzen C, Topping B. Rugby football. Physical medicine and rehabilitation clinics of North America 1999;10(1):159-175.

20. Du Toit DE, Olivier P, Grenfell L, Eksteen B. Isokinetic neck strength norms for schoolboy rugby forwards. South African Journal of Sports Medicine 2005;17(1):1926.

21. Hendricks S, Lambert M. Tackling in rugby: Coaching strategies for effective technique and injury prevention. Int J Sports Sci Coaching 2010;5(1):117-136. [http://dx.doi.org/10.1260/1747-9541.5.1.117]

22. Viljoen W, Patricios J. BokSmart - implementing a National Rugby Safety programme. Br J Sports Med 2012;46:492-493. [http://dx.doi.org/10.1136/ bjsports-2012-091278]

23. Lark SD, McCarthy PW. Cervical range of motion and proprioception in rugby players versus non-rugby players. J Sports Sci 2007;25(8):887-894. [http://dx.doi. org/10.1080/02640410600944543] 